\title{
A BNCC e o Currículo da Educação Infantil e do Ensino Fundamental em Sergipe
}

\author{
BNCC and the Curriculum of Childhood Education and Fundamental \\ Education in Sergipe
}

\section{La BNCC y el Currículo de la Educación Infantil y de la Enseñanza Fundamental en Sergipe}

\author{
Paulo Sergio Marchelli' \\ Universidade Federal de Sergipe, Professor Associado. \\ https://orcid.org/0000-0003-3327-3403
}

Resumo: A implementação da Base Nacional Comum Curricular (BNCC) em curso no sistema brasileiro da Educação Básica apresenta características regionais específicas, que dependem de opções políticas e estratégias de gestão assumidas pelas diversas instituições envolvidas direta ou indiretamente com o processo. Nesse sentido, o objeto de estudo do presente trabalho consiste no levantamento e análise de documentos e discursos produzidos por instituições e seus agentes atrelados ao processo de implementação da BNCC no estado de Sergipe, compreendendo especialmente a Secretaria Estadual de Educação, a Secretaria Municipal de Educação de Aracaju e a Universidade Federal de Sergipe. A investigação fundamenta-se, assim, na pesquisa documental e na apresentação de narrativas que exprimem vivências e emitem opiniões sobre o objeto de estudo contemplado. Com isso, por meio do enfoque metodológico da análise de documentos e de narrativas é apresentado um quadro geral dos aspectos mais importantes observados nesse momento sobre questões curriculares no sistema educacional deste Estado. Priorizou-se a Educação Infantil e o Ensino Fundamental, desde que o Currículo de Sergipe voltado para estas etapas da Educação Básica em suas diversas modalidades encontra-se no momento aprovado pelo Conselho Estadual de Educação e homologado pelas instâncias políticas locais. A pesquisa mostra como os documentos e as narrativas produzidos sobre o currículo são formados a partir do embate entre propostas centralizadas, como é o caso da BNCC e o equacionamento necessário para a formulação de políticas públicas voltadas à superação de dificuldades regionais e contingentes da Educação Básica.

Palavras-chave: BNCC. Implementação curricular. Estado de Sergipe. Narrativas. Análise documental.

Pós-doutor em Educação pela Universidade do Estado do Rio de Janeiro; Doutor em Educação pela Universidade de São Paulo. 
Abstract: The implementation of the National Curriculum Common Core (BNCC) underway in the Brazilian Basic Education system has specific regional characteristics, which depend on political options and management strategies assumed by the various institutions directly or indirectly involved with the process. In this sense, the present work aims to present a survey and an analysis of documents and narratives produced by institutions and their agents linked to the process of implementation of the BNCC in the state of Sergipe, comprising especially the State Department of Education, the Municipal Department of Education of Aracaju and the Federal University of Sergipe. The investigation is based, therefore, on documentary research and the presentation of narratives that express experiences and issue opinions on the object of study contemplated. Thus, through the methodological approach of document and narrative analysis, a general picture of the most important aspects observed at that time about curricular issues in the educational system of this state is presented. Early childhood education and elementary education were prioritized, since the Sergipe Curriculum focused on these stages of Basic Education in its various modalities is currently approved by the State Education Council and approved by local political bodies. The research shows how documents and narratives produced on the curriculum are formed from the clash between centralized proposals, such as the case of BNCC and the necessary solution for the formulation of public policies aimed at overcoming regional and contingent difficulties in Basic Education.

Keywords: Curricular Implementation. Sergipe, Brazil. Narratives. Analysis of documents. National Curriculum Common Core.

Resumen: La implementación de la Base Nacional Común Curricular (BNCC), en vigor en el sistema brasileño de Educación Básica, presenta características regionales específicas que dependen de las orientaciones políticas y de las estrategias de gestión llevadas a cabo por las diferentes instituciones involucradas directa o indirectamente en el proceso. En ese sentido, el objeto de estudio del presente trabajo consiste en el levantamiento y análisis de documentos y discursos realizados por instituciones y agentes vinculados al proceso de implementación de la BNCC en el estado de Sergipe, comprendiendo especialmente a la Secretaría Estadual de Educación, la Secretaría Municipal de Educación de Aracaju y la Universidad Federal de Sergipe. La investigación se basa, de este modo, en la investigación documental y la presentación de narrativas que registran experiencias y emiten opiniones sobre el objeto de estudio contemplado. Con esto, por medio del enfoque metodológico del análisis de documentos y del estudio narrativo, se presenta un cuadro general de los aspectos más importantes observados en este momento sobre cuestiones curriculares en el sistema educativo de este Estado. Se dio prioridad a la Educación Infantil y a la Enseñanza Fundamental, debido a que el Currículo de Sergipe orientado para estas etapas de la Educación Básica en sus diversas modalidades se encuentra en este momento aprobado por el Consejo Estadual de Educación y homologado por las instancias políticas locales. El estudio muestra como los documentos y las narrativas producidos sobre el currículo están formados a partir de la confrontación entre las propuestas centralizadas, como es el caso de la BNCC, y las resoluciones 
necesarias para la formulación de políticas públicas orientadas a la superación de las dificultades regionales y derivadas de la Educación Básica.

Palabras-clave: Implementación curricular. Estado de Sergipe. Narrativas. Análisis documental. Base Nacional Común Curricular.

Recebido em 16 de abril de 2020

Aceito em 27 de outubro de 2020

\section{INTRODUÇÃO}

No dia 15 de dezembro de 2017, em Brasilia, a Base Nacional Comum Curricular (BNCC ou Base) foi aprovada por 20 votos a 3 pelo Conselho Nacional de Educação (CNE). Cinco dias depois, em 20 de dezembro, o Ministério da Educação (MEC) procedeu a homologação do documento em uma cerimônia que contou com a presença do Presidente da República e do Ministro da Educação (MOVIMENTO PELA BASE, 2017a; FUNDAÇÃO LEMANN, 2017). As referências aqui consideradas são de duas organizações, o Movimento pela Base Nacional Comum e a Fundação Lemann, que publicaram em primeira mão os eventos citados em seus sites. Estas organizações tiveram um papel relevante no que tange à caracterização dos principais setores da sociedade civil com interesses específicos e participação ativa em todo o processo que culminou no ato de aprovação e na cerimônia de homologação noticiados.

0 Movimento pela Base foi fundado em 2013 como entidade não governamental por um grupo de pessoas físicas e organizações diversas do setor educacional, tendo por meta a causa da Base Nacional Comum Curricular (MOVIMENTO PELA BASE, 2015, 2017a, 2017b). Possuindo um espaço privilegiado de ação política, o Movimento pela Base assessora os órgãos reguladores centrais da educação brasileira no processo de implementação da BNCC, dificultando a participação coletiva e o debate democrático construído sob a forma de audiências e consultas públicas. Desde o início da produção do documento e visando sua implementação depois de homologado, esse Movimento tem procurado garantir espaços de ação junto às redes de ensino e às escolas por meio da defesa de visões sobre o currículo que mesmo amplamente pertinentes são manipuladas para fins de permitirem consultorias futuras.

Importante ressaltar que o documento da Base Nacional Comum não deverá incluir detalhamento como cada objetivo de aprendizagem deve ser ensinado. Nesse aspecto é importante reconhecer que há necessidades específicas, geradas pelo perfil do aluno atendido, história da comunidade ou mesmo opção pedagógico-epistemológica das equipes locais, que impactam 
e caracterizam a pedagogia a ser usada em cada escola. (MOVIMENTO PELA BASE, 2015, p. 4).

A Fundação Lemann, por sua vez, fundada há 15 anos, registra em seu portfólio na Internet que ao longo de sua história sempre trabalhou por uma educação pública de qualidade e voltada para todos os cidadãos, de forma que se apresenta como uma organização cuja vida foi dedicada a solucionar os principais desafios sociais do Brasil (FUNDAÇÃO LEMANN, 2017, 2020). Segundo sua própria descrição, trata-se de uma organização familiar e sem fins lucrativos, que atua em parceria com governos e entidades da sociedade civil, contemplando a pluralidade do pensamento e a prática inclusiva sobre a educação, disposta a trilhar caminhos que contribuem para a escalada redentora dos principais desafios brasileiros. A Fundação Lemann é uma das principais mantenedoras do Movimento Todos pela Educação, organização da sociedade civil sem fins lucrativos, plural, suprapartidária, independente e que não recebe recursos públicos (TODOS PELA EDUCAÇÃO, 2020). Foi fundada em 6 de setembro de 2006 no Museu do lpiranga, em São Paulo, no mesmo local da proclamação da Independência do Brasil, um dia antes de seu aniversário. Na ocasião, foi apresentada a Carta de Compromissos do Movimento Todos Pela Educação, que pretendia ser um marco histórico na construção da escola de qualidade para todos, propondo melhorar o Brasil por meio do impulsionamento do acesso à educação e da equidade social.

A princípio, considerando as posições que divulgam, o Movimento pela Base e o Todos pela Educação parecem estar voltados estritamente para a ideia de representarem canais de interlocução democrática da BNCC com a sociedade, motivados pela visão de construir por meio da educação um país socialmente justo, em que a oportunidade de crescimento pessoal e ampliação da cidadania são oferecidas a todos indistintamente. No entanto, esta aparência progressista esconde uma faceta privatista em relação à educação pública, inserida em uma rede formada por grupos econômicos que, espalhados pelo mundo, se mostram dispostos a influir nas tomadas de decisões pelos governos, para fazer prevalecer seus interesses em relação às políticas educacionais (FIERA, 2019). Tais Movimentos funcionam como uma grande rede de agregação do dinheiro circulante no capitalismo contemporâneo, interessada em obter lucros a partir de investimentos na gestão das politicas públicas educacionais.

Entre outras mantenedoras destes dois Movimentos, destacam-se os maiores grupos financeiros atuantes no Brasil, o Banco Itaú, o Unibanco e o Bradesco; grandes empresas industriais, como a Votorantim que produz cimento, a Gerdau do ramo do aço e a fábrica Suzano de papeis; a Telefônica do setor de comunicações; a Gol Transportes Aéreos; a Natura do mundo dos perfumes; a família Abílio Diniz; etc. Cada um desses grupos possui um braço de atuação socioeducacional caracterizado por Fundações, Institutos e outras espécies de organizações reconhecidas pela legislação brasileira, que mantêm o Movimento pela Base e o Todos pela Educação em funcionamento, de forma a garantir uma 
homogeneidade não-concorrencial na apropriação como lucro de parte significativa do capital aplicado pelo Estado na educação pública. "Os grandes grupos econômicos presentes na composição das mantenedoras do movimento TPE [Todos pela Educação] têm desempenhado papel estratégico para cimentar o consenso quanto à hegemonia do capital financeiro." (FIERA, 2019, p. 10). 0 Movimento pela Base e o Todos pela Educação constituem assim a atuação do chamado "Terceiro Setor" no sistema de ensino público brasileiro, cujo propósito é fazer interferências e apresentar modificações a partir de um ponto de vista não governamental.

\begin{abstract}
Constatamos que tais interferências estão pautadas na teoria do capital humano, de forma que os futuros trabalhadores devem ser formados para garantir o processo de mundialização e acumulação de capital. Para esse segmento da sociedade civil, a educação é vista como um importante meio para o processo de acumulação de capital, sendo também uma forma de legitimar o consenso da reprodução injusta do sistema de classes. (D’ÁVILA, 2013, p. 11558).
\end{abstract}

Em particular, a Fundação Lemann está interessada em interferir nas políticas de formação de professores da educação básica pública, com o intuito de melhorar o "capital humano" atuante nas escolas, e propõe que a qualidade do aprendizado dos alunos somente será significativa quando o trabalho docente for realizado segundo "padrões adequados de gestão" (D’ÁVILA, 2013). A teoria do capital humano, preconizada em termos das 10 Competências Gerais da BNCC, apresenta-se como caráter normativo do documento, definindo de forma orgânica e progressiva o conjunto das aprendizagens essenciais que se constituem como direitos do aluno no âmbito da Educação Básica. Esta mesma concepção é a que orienta hoje a implementação da BNCC pelas redes e instituições escolares, materializando projetos do setor empresarial no interior da educação pública, que passa a ser concebida apenas como um sistema de formação técnica do trabalhador do futuro, voltado a produzir bens e riquezas para o país.

No âmbito do pensamento sobre o currículo, mesmo que propale explicitamente o contrário, o Terceiro Setor assume de forma substancial o princípio de conceber a centralidade do processo como necessária para uma educação de qualidade. A produção teórica não é exatamente a especialidade dos membros do Terceiro Setor, pois eles são essencialmente "práticos", de forma que suas teses pouco analíticas constituem intuições formadas a partir de experiências quase sempre irrefletidas sobre o amplo significado da educação. No entanto, visando à instrumentalização teórica que lhe faz falta, a Fundação Lemann vem investindo na formação de quadros capacitados para a fundamentação de suas teses no debate político. A deputada federal Tabata Amaral, formada em ciências políticas e astrofísica pela Universidade de Harvard sob os auspícios da Fundação Lemann e fenômeno de votos nas eleições de 2018 , é um exemplo desse investimento. "[...] vale lembrar a fala fortemente crítica de Tabata Amaral 
frente ao Ministro Vélez no Congresso Nacional. Tabata, deputada federal pelo PDT de São Paulo, formada no exterior com bolsa da Fundação Lemann, é uma das profissionais atuantes no Todos pela Educação." (LOPES, 2019, p. 7, grifo do autor).

Para materializar o pensamento do Terceiro Setor sobre o currículo, pode-se recorrer a um video em que um dos seus membros expõe ideias que estão presentes na gênese da elaboração da BNCC no país (LACERDA, 2012). Na época em que a base comum era ainda uma poltitica apenas prevista na legislação educacional e a discussão voltada à sua produção não havia iniciado, a expositora registrava no vídeo a possibilidade da criação de um currículo escolar nacional e unificado para diminuir as desigualdades educacionais do país, 0 que vai se consubstanciar depois com a BNCC:

\begin{abstract}
Nós não estamos falando de listagem de conteúdos, mas de marcos, de explicitações concretas para que as aprendizagens esperadas possam acontecer. 0 que eu acho que é o grande avanço do nosso debate é que nós queremos dizer o que as crianças devem aprender ao final do primeiro ciclo, ao final do primeiro ano, do quinto ano, do sexto ano. (LACERDA, 2012, $10 \mathrm{~min}$ 40seg-11min 12 seg).
\end{abstract}

Esta fala caracteriza flagrantemente a tentativa de na época citada conduzir a discussão sobre as aprendizagens esperadas que a BNCC iria protagonizar posteriormente para o palco que o Terceiro Setor estava montando com vistas à representação de discursos embasados na Teoria do Capital Humano. 0 caráter da BNCC de ser um documento normativo "que define o conjunto orgânico e progressivo de aprendizagens essenciais que todos os alunos devem desenvolver ao longo das etapas e modalidades da Educação Básica l..." (BRASIL, 2017b, p. 7, destaque do documento), favorece a atuação de grupos de interesses privados junto às redes de ensino públicas, designadas a capitanear a implementação da BNCC no país. De fato, verifica-se que quanto mais o currículo se fecha em torno das aprendizagens essenciais, mais ficam atreladas ao órgão político de decisão central configurado pelo MEC as determinações sobre os processos referentes à formação de professores, à avaliação, à elaboração de conteúdos educacionais, à adoção de modelos de gestão e aos critérios para a oferta de infraestrutura adequada ao pleno desenvolvimento da educação. Assim, com os braços estendidos para o governo central e por este acolhidas, as organizações do Terceiro Setor candidatam-se e são eleitas para atuarem junto às redes de educação dos Estados e Prefeituras.

Logo a seguir à aprovação e homologação do documento da Base, em 22 de dezembro de 2017 o CNE publica uma Resolução que determina a obrigatoriedade de sua implementação ao longo das etapas da Educação Básica em suas diversas modalidades, instituindo e orientando a forma por meio da qual o processo deverá ser realizado (BRASIL, 
2017c). 0 Artigo $7^{\circ}$ da Resolução do CNE determina que caberá aos órgãos normativos dos Sistemas de Ensino aos quais as instituições ou redes escolares do país estão atreladas a consideração da BNCC como referência obrigatória e a definição das normas complementares para a inclusão da parte diversificada nos seus currículos, o que será produzido de acordo com a Lei de Diretrizes e Bases (LDB), as Diretrizes Curriculares Nacionais (DCN) e o atendimento das necessidades educacionais locais das respectivas regiões. No Parágrafo único do Artigo $7^{\circ}$ fica estabelecido que a parte comum e a diversificada "não podem ser consideradas como dois blocos distintos justapostos, devendo ser planejadas, executadas e avaliadas como um todo integrado" (BRASIL, 2017c, p. 6). É importante destacar que a Resolução do CNE procura instrumentalizar as atribuições dos órgãos normativos dos sistemas regionais de ensino em termos da diferenciação que devem fazer entre a proposta pedagógica e o currículo.

A proposta pedagógica deverá identificar a realidade do lugar e do tempo nos quais as aprendizagens serão constituídas; definir estratégias interativas e colaborativas para a gestão do ensino e da aprendizagem; selecionar metodologias e procedimentos didático-pedagógicos diversificados para contemplar as necessidades dos alunos em termos das suas famílias, a cultura das suas comunidades de origem e seus grupos de socialização; explicitar os processos de motivação e engajamento dos estudantes nas aprendizagens; estabelecer princípios de avaliação formativa de processo ou de resultado na escola; discutir a melhoria do desempenho da instituição escolar, dos professores e dos alunos; selecionar e avaliar recursos didáticos e tecnológicos para apoio ao processo de ensino e aprendizagem; apresentar materiais de orientação para os professores; explicar como a escola ou a rede de ensino manterá processos contínuos de reorganização da sua gestão pedagógica e curricular; dizer quais serão as estratégias adotadas pela instituição escolar ou pela rede de ensino para a produção do currículo a partir do projeto pedagógico.

A proposta pedagógica e o currículo devem ser considerados, portanto, como dois documentos diferentes e complementares. Entende-se que a produção da primeira é função dos estabelecimentos escolares, mas o outro deve ser elaborado tanto por estes últimos quanto pelos sistemas de ensino dentro dos quais eles se inserem. A própria LDB quando aprovada em 1966 já assumia que a sistemática de produção dos currículos a partir de uma base comum deve contemplar uma parte diversificada "em cada sistema de ensino e em cada estabelecimento escolar [...]” (BRASIL, 2017a, p. 19, destaques do autor). Mas há uma exclusão lógica na assertiva da Resolução do CNE em questão, quando assevera que "as propostas pedagógicas das instituições ou redes de ensino" (BRASL, 2017c, p. 5, grifo do autor) cumprem a função de orientar o desenvolvimento dos currículos de seus cursos. Deve-se, portanto, considerar que tanto os estabelecimentos escolares quanto as redes de ensino produzirão cada um o seu currículo, mas a proposta pedagógica não precisa ser necessariamente feita por ambos. Ela está presente, de fato, em todas as escolas, mas nem sempre nas redes de ensino. 
Em meio a este quadro geral caracterizado por iniciativas do sistema público e jogos de interesse de setores privados é que se dá a produção do Currículo de Sergipe para a Educação Infantil e o Ensino Fundamental. A apresentação e análise desta produção, objetivo do presente artigo, faz-se mediante a opção metodológica pela pesquisa documental e pela apresentação de narrativas realizadas sobre o processo de construção do documento.

A análise documental é apresentada na seção 2 e contempla fundamentar a produção do currículo em questão tendo em vista o levantamento dos principais instrumentos legais e guias de orientação, a começar pela própria BNCC, que subsidiaram o processo de implementação realizado. Objetiva-se demonstrar nesta seção de que forma as redes educacionais públicas envolvidas interpretaram os subsídios oferecidos e agiram no sentido de redigir seu documento final. Pode-se verificar por meio do material apresentado na análise documental que as políticas públicas circulantes em torno da implementação da Base levaram - currículo sergipano a alcançar um elevado grau de clareza sobre as necessidades educacionais mais prementes do Estado, mas por outro lado também limitaram a abrangência conceitual necessária para se chegar a um documento autenticamente original.

Para estabelecer uma base empírica associada à discussão trazida por este artigo, a seção 3 apresenta narrativas construídas a partir de manifestações proferidas por professores universitários e gestores da Educação Básica como histórias que sendo vividas e contadas apresentam informações cruciais sobre a produção do currículo nos espaços em que eles trabalham, imaginando conceitos e suscitando ações. Uma narrativa pode ser sensível à captação de todos os tipos de nuances que ocorrem nos espaços de produção do currículo, desde que se esteja atento à complexidade das informações expressas pelos que dialogam sobre suas vivências. "Conversas animadas, por exemplo, simplesmente acontecem. Mas, captar as nuances dessas vivências, nos textos de campo, é algo complexo e cheio de ambiguidades." (CLANDININ; CONNELLY, 2015, p. 132). Dessa forma, mesmo que o material apresentado não contemple em essência a construção de um texto de campo na perspectiva da pesquisa narrativa considerada no trabalho dos autores citados, ele é suficientemente esclarecedor no que diz respeito às vivências e expectativas dos narradores sobre a abrangência e as fronteiras do currículo construído em Sergipe.

\section{O CURRÍCULO DO ESTADO DE SERGIPE: ALCANCES E LIMITES}

No dia 05 de abril de 2018, a União Nacional dos Dirigentes Municipais de Educação (UNDIME) noticiou em seu site o lançamento do Guia de implementação da Base Nacional Comum Curricular (UNIÃO NACIONAL DOS DIRIGENTES MUNICIPAIS DE EDUCAÇÃO, 2018). Os signatários do 
documento foram o MEC, o Conselho Nacional de Secretários de Educação (Consed), a UNDIME, o Fórum Nacional dos Conselhos Estaduais e Distrital de Educação (FNCEE) e a União Nacional dos Conselhos Municipais de Educação (UNCME), contando com o apoio técnico do Movimento pela Base Nacional Comum. 0 Guia define sete ações transversais para a implementação da BNCC, denominadas dimensões, com o objetivo de subsidiar o trabalho das secretarias de educação estaduais e municipais, apresentando sugestões e materiais de apoio, compreendendo: estruturação da governança da implementação, estudo das referências curriculares, (re) elaboração curricular, formação continuada para os novos currículos, revisão dos projetos pedagógicos, materiais didáticos e avaliação e acompanhamento da aprendizagem (GUIA DE IMPLEMENTAÇÃO BNCC, 2018).

As orientações definidas pelo Guia foram seguidas de uma forma geral pelos sistemas de ensino de todo o Brasil, sendo que em Sergipe houve um acordo entre a Secretaria de Estado da Educação (SEED) e as Secretarias Municipais de Educação para a realização de um trabalho conjunto, com a adesão de todos os 75 municípios existentes. 0 ponto principal do trabalho foi a produção do Currículo de Sergipe para a Educação Infantil e $\circ$ Ensino Fundamental, de forma que uma versão preliminar foi colocada para consulta pública no dia 10 de agosto de 2018 em uma solenidade de apresentação do documento, que se estendeu até o dia 18 de setembro seguinte. Durante o período da consulta pública foram realizados oito Seminários Regionais para debates sobre o documento, bem como os Dias "C", reservados para que Escolas, Municípios e Diretorias Regionais de Educação (DRE) pudessem discuti-lo. No dia 12 de novembro de 2018, uma versão que incorporava as sugestões oriundas da consulta pública foi entregue em uma solenidade pelo Secretário de Educação à presidenta do Conselho Estadual de Educação (CEE), que emitiu parecer favorável à sua aprovação e em 13 de dezembro de 2018 fez publicar no Diário Oficial do Estado a Resolução Normativa n 4, de 29 de novembro de 2018, que regulamenta a implementação do Currículo de Sergipe nas instituições educacionais integrantes do seu sistema de ensino (SERGIPE, 2018b).

A equipe de coordenação e redação do Currículo de Sergipe elegeu oito princípios norteadores, que foram referendados na Consulta Pública e apareceram descritos no documento como elementos para a realização harmônica da educação integral. A educação integral é prevista como voltada para o desenvolvimento pleno dos educandos, contemplando, entre outros fundamentos conceituais do texto da BNCC, a justiça social e o aperfeiçoamento da vida democrática, constituindo-se em: colaboração, respeito à diferença, criticidade, inclusão, equidade, autonomia, sustentabilidade e criatividade (SERGIPE, 2018a). Dessa forma, o texto criado pelos redatores do Currículo de Sergipe apresenta uma estrutura que segue o padrão proposto pela BNCC, reproduzindo o que talvez tenha sido circunstancial na produção do documento para as etapas consideradas em todos os estados brasileiros, contendo em geral: apresentação; texto introdutório; exposição da etapa da Educação Infantil com sua caracterização histórica e política locais, seus fundamentos filosófico-pedagógicos 
e os elementos da sua organização curricular segundo os campos de experiências definidos pela Base; abordagem sobre a etapa do ensino fundamental, compreendendo sua contextualização local e apresentação do currículo em termos das competências e formação de habilidades específicas dentro das cinco áreas de conhecimento definidas pela Base que lhe são pertinentes: Linguagens, Matemática, Ciências da Natureza, Ciências Humanas e Ensino Religioso.

Não obstante a reprodução da estrutura geral da BNCC protagonizada pelo Currículo de Sergipe, sua padronização dos códigos referentes aos objetivos de aprendizagem e desenvolvimento da Educação Infantil, bem como do conjunto das habilidades associadas aos componentes curriculares apresentam-se segundo uma caracterização própria, o que é explicado nos seguintes termos:

\footnotetext{
A estrutura da BNCC trouxe a padronização dos códigos no intuito de garantir a compreensão de todos os professores no momento de planejar suas aulas, tomando como referência cada objetivo de aprendizagem na Educação Infantil e habilidade dos componentes curriculares nas áreas específicas do conhecimento, no Ensino Fundamental, identificados pelo código alfanumérico.

0 código alfanumérico, que demarca cada objetivo de aprendizagem e habilidade, está alinhado à proposta da BNCC. Para os novos objetivos de aprendizagem e habilidades criados por Sergipe foi acordado entre os redatores garantir a padronização da estrutura da Base, que seguiram o seguinte critério: 0 primeiro e o segundo par de letras do código e o primeiro par de números, ambos lidos da esquerda para direita, permanecem com o mesmo critério da BNCC. Porém, o segundo par de números dessa sequência do código alfanumérico iniciará para cada ano e/ou ciclo de acordo com a progressão cognitiva, sendo numerada na ordem 01,02, 03, e assim sucessivamente, destacando que são espećficos do Currículo de Sergipe. 0 código terá um par de letras no final da sequência com a sigla SE (Ex: EF08MA01SE, EF: Ensino Fundamental; 08: oitavo ano; MA: Matemática; 01: sequência em que está escrita no currículo; SE: Sergipe). (SERGIPE, 2018a, p. 16).
}

Para compreender a peculiaridade dos componentes curriculares específicos do Currículo de Sergipe em relação aos que são gerais na Base, é preciso destacar na citação acima a informação de que o segundo par de números do código alfanumérico, que indica a posição da habilidade dentro da sequência dos anos ou ciclos escolares, está de acordo com a progressão cognitiva de formação desta mesma habilidade. A título de exemplo, considere-se o campo de experiências "traços, sons, cores e formas" para bebês (zero a 1 ano e 6 meses). Além dos três objetivos de aprendizagem e desenvolvimento propostos pela BNCC, o Currículo de Sergipe apresenta mais dois: "(EI01TS01SE) conhecer seu próprio corpo e seus sons, através de pinturas, danças e musicalização; (El01TS02SE) manipular instrumentos riscantes e tintas, utilizando partes do corpo, produzindo suas marcas." (SERGIPE, 2018a, 
p. 75). Isso significa que haveria uma progressão cognitiva do primeiro para o segundo componente, mas pergunta-se: 0 que fará a criança, depois de conhecer seu próprio corpo e os sons com ele produzidos, se solicitada a manipular instrumentos que produzam outros sons? Sabe-se que a respeito da aplicação de esquemas cognitivos conhecidos a situações ainda não vivenciadas, "quando a criança se encontra na presença de objetos ou fenômenos inteiramente novos para ela, [...] não pode propor-se a qualquer fim preciso, mas, tão somente, 'compreendê-los'." (PIAGET, 1987, p. 240). Dessa forma, não se pode garantir que que haja uma progressão cognitiva entre as aprendizagens assinaladas pela sequência dos componentes curriculares acima. A princípio, não seria recomendável priorizar no campo da produção do currículo o trabalho com hierarquias de aprendizagens cognitivamente esperadas.

0 documento da BNCC chama a atenção para este problema, no sentido de destacar que "o uso de numeração sequencial para identificar as habilidades de cada ano ou bloco de anos não representa uma ordem ou hierarquia esperada das aprendizagens." (BRASIL, 2017b, p. 31). Assim, na Base, a progressão das aprendizagens, presentes na composição dos quadros correspondentes a cada ano ou bloco de anos, pode tanto estar relacionada a processos cognitivos quanto à expectativa de uma crescente sofisticação ou complexidade dos objetos de conhecimento que formam as habilidades associadas aos componentes curriculares.

Com isso, o Currículo de Sergipe parece ter se decidido por uma estratégia incomum, senão contraditória, constituida pelo fato de transgredir a regra áurea de que no campo da organização dos componentes curriculares não se deve priorizar o trabalho com progressões cognitivas oriundas de aprendizagens esperadas. Mas, se esta estratégia se configura como um erro crasso dos redatores do documento de Sergipe, o mesmo não parece ter ocorrido quando eles se colocaram a atender à aqui já citada perspectiva traçada pela da LDB de que os currículos da Educação Infantil e do Ensino Fundamental terão uma base comum e ser complementada por uma parte diversificada, definida em cada sistema de ensino e em cada estabelecimento escolar pelas características regionais e locais da sociedade, da cultura, da economia e dos educandos. Assim é que os redatores cuidaram para que sobre a parte diversificada do Currículo de Sergipe não pairasse nenhuma dúvida: foram logo desmembrando as tabelas dos componentes dos campos de experiências de cada etapa da Educação Infantil em uma coluna sobressalente denominada "abordagem das experiências de aprendizagem". Nesta coluna, os redatores sugerem procedimentos didáticos, o que não está presente no documento original da Base, preocupando-se em fornecer às instituições de Educação Infantil ideias de práticas que teoricamente irão despertar a curiosidade da criança e leva-la a fazer indagações diante da manipulação de objetos materiais e simbólicos presentes localmente em seu mundo de experiências. 
A título de exemplo, veja-se os procedimentos didáticos para o campo de experiências "traços, sons, cores e formas" da Educação Infantil que o Currículo de Sergipe apresenta nesta sua coluna exclusiva:

\begin{abstract}
Explorações e descobertas como experimentar diferentes instrumentos riscantes e tipos de tintas em diferentes suportes, deixando suas marcas gráficas. Também são interessantes objetivos relacionados à intencionalidade de realizar marcas gráficas, como explorar e reconhecer diferentes movimentos gestuais. Pode-se utilizar instrumentos típicos de sua região, representados por folhas, sementes, flores e terra de diferentes cores etc., além de abordar atitudes a serem desenvolvidas relacionadas ao aprendizado e ao currículo com o próprio corpo e dos colegas nessas explorações; [...] (SERGIPE, 2018a, p. 75, grifo do autor).
\end{abstract}

No caso do Ensino Fundamental, os redatores de Sergipe criaram uma coluna própria denominada "especificação dos objetos de conhecimento" para tratar didaticamente cada objetivo de aprendizagem proposto pela BNCC, sugerindo procedimentos que contemplam as vivências do aluno realizadas em seu mundo físico e simbólico reais para a formação das habilidades expressas pelos componentes curriculares.

A título de exemplo, veja-se que na Base do Ensino Fundamental a Área de Linguagens é composta por unidades temáticas e objetos de conhecimentos dos seguintes campos: Língua Portuguesa, Arte, Educação Física e, nos Anos Finais, Língua Inglesa. Dentro do campo da Arte, a Base define uma unidade temática denominada "Artes Visuais"; dentro desta, há um objeto de conhecimento denominado "Sistemas de Linguagem". Para este objeto, aparece o componente curricular "(EF15AR07) Reconhecer algumas categorias do sistema das artes visuais (museus, galerias, instituições, artistas, artesãos, curadores etc.)." (BRASIL, 2017b, p. 201). Para este código, o Currículo de Sergipe irá especificar procedimentos didáticos com base na ideia de visitar o Museu Municipal para conhecer a história da localidade, ir às feiras de artesanato para apreciar artefatos culturais regionais e participar de exposições dos artistas locais. Além disso, na coluna das habilidades é acrescentado um componente de código "(EF15AR02SE) Conhecer e diferenciar os tipos de artes existentes no Brasil, em Sergipe e em seu município." (SERGIPE, 2018a, p. 142).

Pode-se dizer, portanto, que no âmbito da parte diversificada o Currículo de Sergipe se sai muito bem, mesmo que se possa questionar se a apresentação dos procedimentos didáticos devesse aparecer não como "especificação dos objetos de conhecimento", mas sim em termos de algo do tipo "atividades básicas a serem desenvolvidas", em uma coluna à direita da descrição das habilidades. Afinal, parece mais sensato admitir que as práticas didáticas devam se referir diretamente aos componentes curriculares, portanto às habilidades no caso da BNCC e não aos objetivos de aprendizagem. Pode-se compreender que este 
problema é bastante complexo e difícil de ser resolvido, aparecendo mesmo na BNCC como algo que constitui um tipo de contradição conceitual do documento. Veja, por exemplo, o componente definido pela BNCC para o campo da Arte do $1^{\circ}$ ao $5^{\circ}$ anos do Ensino Fundamental “(EF15AR02) Explorar e reconhecer elementos constitutivos das artes visuais (ponto, linha, forma, cor, espaço, movimento etc.)." (BRASL, 2017b, p. 201). Ora, esse componente está redigido de uma forma que se parece muito mais com um objetivo de aprendizagem do que com uma habilidade. Esta deveria ser entendida como algo que foi formado pelas aprendizagens e não como um objetivo destas, havendo mais clareza se no caso do componente destacado a redação fosse: (EF15AR02) Demonstração da capacidade de identificar os elementos constitutivos das artes visuais, (ponto, linha, forma, cor, espaço, movimento etc.), realizada por meio da exploração de artefatos artísticos apresentados pelo professor.

Essa discussão permite entrever o contexto político da produção do Currículo de Sergipe, que, sob o vaticínio dos interesses nacionalmente sedimentados do Terceiro Setor, não conseguiu apresentar um documento onde os erros estratégicos fossem menos abundantes. A forte pressão para que os redatores trabalhassem de uma forma aligeirada foi responsável pelos erros constatados. Isso poderá ser visto na discussão a seguir apresentada, na qual a voz dos agentes institucionais diretamente atrelados ao processo de produção do currículo estadual e de sua implementação esclarece detalhes da situação encontrada.

\section{A UOZ DE PROFESSORES UNIUERSITÁRIOS E DE GESTORES DA EDUCAÇÃO BÁSICA SOBRE A IMPLEMENTAÇÃO DA BNCC EM SERGIPE}

No dia 19/02/2020, às 19h, realizou-se na Universidade Federal de Sergipe (UFS) uma Roda de Conversa sobre a Base Nacional Comum Curricular (BNCC), como parte da programação do II Colóquio Interfaces Acadêmicas entre Graduação e Pós-Graduação, promovido pelo Grupo de Estudos e Pesquisas em Formação de Professores e Tecnologias da Informação e Comunicação (FOPTIC). Estiveram presentes os seguintes debatedores: o autor do presente artigo; Isabella Silva dos Santos, Coordenadora do Ensino Médio da Secretaria de Estado da Educação de Sergipe (SEED); João Manoel de Faro Neto, Coordenador de Formação da SEED para a Educação Infantil e o Ensino Fundamental e membro da equipe de redação do Currículo de Sergipe; Silvana Aparecida Bretas, professora da UFS e assessora pedagógica e de políticas públicas do Sindicato dos Trabalhadores em Educação Básica da Rede Oficial do Estado de Sergipe; Ana Débora Lima de França, Coordenadora de Ensino Fundamental da Secretaria Municipal da Educação de Aracaju (SEMED); Marcos André de Souza, Técnico em Educação da SEMED e Articulador de Língua Portuguesa do Programa Hora de Estudos 
desta Secretaria, voltado para a formação continuada de professores. A sessão contou com a presença de um amplo público interessado, constituído por professores do ensino superior e da educação básica, bem como por alunos da graduação e da pós-graduação da UFS.

As falas proferidas na roda de conversa concretizada serão aqui tratadas mediante o consentimento livre e esclarecido dos participantes como dados de um estudo de campo produzido a partir de manifestações que exprimem vivências e opiniões sobre - Currículo de Sergipe e a implementação da BNCC neste Estado. Os participantes deram anuência para que suas falas fossem identificadas pelos nomes que lhes são próprios, de forma que se tem: Paulo, Isabella, João Manoel, Silvana, Ana Débora e Marcos André.

Paulo, o autor do presente artigo foi o mediador da sessão constituída pela roda de conversa, de forma que construiu narrativas em torno dos interesses que possui como signatário de uma pesquisa em andamento, apresentando aos demais participantes questões que pretendiam conduzir suas falas em direção a determinados pontos de articulação em torno dos quais as Seções 1 e 2 acima foram elaboradas.

\begin{abstract}
Uma questão que eu queria deixar, que acho extremamente importante, que poderíamos tentar responder é: não cabe à escola produzir seu próprio currículo? Não se preceitua, para você dar autonomia para a escola, que ela, a partir das diretrizes propostas pela Base, que ela construa o seu currículo, que os professores tenham condições de se aplicarem à produção do currículo daquela escola, com as especificidades particulares dela? Então eu pergunto, gostaria que fosse colocado em debate, desde que isso acontece no Brasil todo, Sergipe não é o único: Como a SEED, a SEMED e as demais Secretarias Municipais do Estado contemplam a produção pelas escolas dos seus documentos específicos, agora que o Currículo de Sergipe está pronto? (Paulo) (informação verbal).
\end{abstract}

Um aspecto sensível a essa fala de Paulo é que ela suscita o problema da ocupação dos espaços de produção curricular nas escolas pelo Terceiro Setor, desde que tanto a SEED quanto a SEMED e as demais Secretarias Municipais não têm políticas específicas para que as unidades de ensino consigam elaborar seus próprios documentos a partir do que foi proposto pela Base e definido no currículo local. Paulo também se interessou em colocar para debate a questão da estratégia adotada pelos redatores do currículo estadual de proporem códigos alfanuméricos baseados em progressões cognitivas para os novos objetivos de aprendizagem e habilidades criados para a parte diversificada, o que potencialmente está em discordância com os princípios gerais da Base.

Outra coisa que percebi no Currículo de Sergipe, diferentemente da Base, vi que ele coloca aqueles componentes curriculares específicos, que têm o código SE no final, como obedecendo a uma progressão cognitiva. Mas 
a Base diz que as habilidades que ela usa não vêm de uma ideia cognitiva. A Base diz que a numeração sequencial que identifica as habilidades não está baseada na ordem esperada das aprendizagens. As habilidades não obedecem, digamos assim, às etapas do desenvolvimento lógico-operatório do Vygotsky e do Piaget. Não é bem por aí que a Base trabalha. Ela deixou mais aberto. Por quê? Eu achei o Currículo de Sergipe excelente por valorizar bastante a regionalidade, as coisas locais. 0 problema não é esse. 0 problema é essa coisa de propor sequências cognitivas para a produção curricular. Isso não contraria uma ideia básica da BNCC? (Paulo) (informação verbal).

A perspectiva destes questionamentos de Paulo foi a de provocar os debatedores para considerarem o que parece ser uma incoerência contundente do Currículo de Sergipe em relação à BNCC, desde que o documento local afirma que os seus componentes curriculares específicos, o segundo par de números do código alfanumérico, que indica a posição da habilidade dentro da sequência dos anos ou bloco de anos, está de acordo com a progressão cognitiva de formação desta mesma habilidade. Seria a progressão cognitiva para a formação das habilidades com o qual o Currículo de Sergipe constrói seus componentes específicos uma ideia diferente das hierarquias esperadas de aprendizagens com a qual a BNCC não trabalha? João Manoel, que foi redator do documento de Sergipe, esclareceu esse ponto em sua narrativa citada mais à frente sobre a metodologia proposta para a construção de habilidades da parte diversificada do currículo. No mesmo sentido, Marcus André, da Rede Municipal de Aracaju, tratou em sua fala a respeito da dificuldade de construir novas habilidades na área de conhecimento da Língua Portuguesa além das que estão na Base.

Outra fala de Paulo apresentou questões dirigidas aos representantes da SEMED sobre as razões de suas limitações para uma produção curricular própria:

Uma questão que eu tenho para os representantes da Secretaria Municipal seria a seguinte: A Base Nacional no plano da produção curricular ela é omissa em relação à autonomia das diversas instância de gestão da educação pública. Quero dizer o seguinte: você tem o MEC, você tem as Secretarias Estaduais e depois as Secretarias Municipais. Os municípios não teriam autonomia em relação ao Estado? Eu sei que há um convênio entre os municípios e o Estado para que os municípios utilizem o Currículo de Sergipe. A pergunta é: Porque as Secretarias Municipais não pensam também em elaborar seu próprio currículo para implementarem a BNCC? Seria em parceria com o Estado, mas independentemente dele. Você tem a Base geral, sessenta por cento e os outros quarenta estariam voltados para as demandas educacionais dos Municípios em especial, não do Estado como um todo. Essa questão me parece importante: Como é que fica a autonomia das redes municipais de Sergipe no processo de implementação da BNCC? (Paulo) (informação verbal). 
Estes questionamentos pretenderam levar aos debatedores o problema das restrições impostas às redes municipais e às escolas em geral pela política adotada no Brasil de produção de um currículo único a nível estadual como forma de implementação da BNCC. Essa política inibiu a produção curricular nas escolas e nas redes municipais, de forma que em Sergipe essa produção autônoma parece ser inexistente. A confusa legislação educacional brasileira criou a atribuição para as escolas de reformularem seus Projetos Político Pedagógicos (PPP) como parte do processo de implementação da Base. 0 Programa de Apoio à Implementação da BNCC - ProBNCC é incisivo ao determinar que cabe aos agentes do regime de colaboração entre Estados e Municípios "articular o processo de disseminação dos novos currículos da Educação Infantil e do Ensino Fundamental e engajamento das redes municipais na sua implementação." (BRASIL, 2019, p. 11). Também é precipuo ao regime de colaboração que os articuladores do ProBNCC planejem e realizem a formação continuada dos profissionais da educação voltada para a implementação dos novos currículos da Educação Infantil e do Ensino Fundamental nas redes municipais e estadual. É oportuno lembrar que os PPP que estão sendo produzidos pelas escolas e as ações de formação de professores de todas as redes são instrumentos que agem estritamente no sentido de operacionalizar didaticamente o currículo único, servindo, portanto, para reforçá-lo. Essa situação alarga também o espaço de atuação das entidades do Terceiro Setor sobre o sistema público de Educação Básica, pois uma vez findados os recursos do ProBNCC, não haverá mais como as redes estaduais e municipais do país arcarem com os custos da formação de professores, a não ser operacionalizando-a por meio de programas externos financiados por fontes que certamente decorrerão de pressões políticas da iniciativa privada sobre o MEC, o que aliás está se dando de forma intensiva no processo de implementação da Base.

A SEED e a SEMED foram convidadas pela UFS por meio do Professor Carlos Alberto de Vasconcelos, coordenador do II Colóquio Interfaces Acadêmicas entre Graduação e Pós-Graduação para enviarem dois representantes de cada um ao evento. Isabella foi designada pela SEED para o colóquio, envolvida que está na produção do Currículo de Sergipe para o Ensino Médio, documento que se encontrava submetido à consulta pública naquele momento.

Quando eu vinha para cá no carro com João, eu fiz uma pergunta. Eu imaginei que seria essa pergunta que vocês iriam nos fazer: 0 que os Estados estão fazendo para implementar a Base? E a resposta é o que o estado de Sergipe está fazendo para implementar a Base. É importante a gente saber que existe um programa de implementação chamado ProBNCC, que é nacional. Todos os estados têm este programa, que contratou por meio de edital redatores, que têm que ser obrigatoriamente professores do ensino básico. Estes redatores são bolsistas do Programa. Então, nesse caso nós não estamos falando de alienígenas que estão escrevendo o currículo, nós estamos falando de professores da rede, seja ela municipal, 
seja ela estadual. No caso do Ensino Médio, que é a pasta pela qual eu repondo, são professores da Rede Estadual. Então, o ponto de partida na implementação da Base no estado de Sergipe é o ProBNCC, por meio desses redatores bolsistas. 0 professor João coordena a formação dos professores que vão trabalhar o Currículo de Sergipe da Educação Infantil e do Ensino Fundamental. A implementação já está na fase de formação, tem também a reavaliação dos PPP e as escolas já enviaram os PPP. (Isabella) (informação verbal).

Estas afirmações apresentam a amarração implementada pela SEED entre a redação do Currículo de Sergipe, a ação de formação dos professores em curso e a produção dos PPP. 0 envio dos projetos pedagógicos das escolas à SEED antes que o processo de formação tivesse encerrado decorre certamente do imbróglio logístico do ProBNCC ao conceber as etapas da implementação, denominadas ciclos. Tem-se que cabe aos professores bolsistas da Educação Infantil e do Ensino Fundamental atuarem inicialmente na elaboração dos currículos para as redes estaduais e municipais, que no caso de Sergipe resumiu-se à redação do documento único aprovado pelo CEE (ciclo 1). "Em seguida, devem atuar na formação dos profissionais da educação das redes estaduais e municipais sobre os novos currículos e na revisão ou elaboração do projeto pedagógico das unidades escolares de acordo com os novos currículos (ciclo 2)." (BRASL, 2019, p. 7). 0 que parece lógico seria o ciclo 2 ser desmembrado em dois passos subsequentes, compreendendo primeiramente a formação e depois a revisão dos projetos pedagógicos, tarefa para a qual os professores após serem formados estariam melhor preparados. Esse ponto reforça a percepção de que no Brasil os PPP constituem quase sempre um documento pouco fiel às necessidades de transformação política e de renovação didático-pedagógica das escolas.

Em uma de suas falas, João Manoel complementou as informações passadas por Isabella ao fazer um balanço do processo de implementação da Base em Sergipe e detalhou determinados aspectos técnicos importantes do processo definido pelo ProBNCC.

Na Resolução 2/2017 do Conselho Nacional de Educação, a partir desse documento com a BNCC já homologada, vem a elaboração dos currículos dos estados a partir de março e abril de 2018. Alguns estados avançaram, outros não. Em Sergipe, os técnicos e professores de todas as secretarias municipais foram convidados a participar, houve ampla divulgação, seminários em todo o território sergipano, em dez Diretorias Regionais com a participação dos municípios circunvizinhos. No regime de colaboração, o município de Aracaju, por exemplo, aqui em Sergipe, assinou um termo de pactuação para a elaboração do documento do currículo estadual. A equipe de trabalho é chamada de ProBNCC, para apoiar que o documento chegue realmente até a sala de aula, para que o professor faça de acordo com o currículo. Então, esse programa tem três ciclos: o ciclo de construção do currículo a partir da Resolução 2/2017, que funcionou em 2018; no ano passado de 2019, o ciclo 2 de formação continuada para implementação do 
currículo alinhada ao documento, termina agora em março de 2020; aí tem o terceiro ciclo, que é o ciclo de acompanhamento da implementação do documento para chegar à sala de aula, que vai até dezembro desse ano. A equipe de redatores tem 27 pessoas. São 2 coordenadores estaduais; 3 coordenadores de etapas, sendo 1 da Educação Infantil e 2 dos anos iniciais e finais; e 22 redatores. Desses 22 redatores, há dois ou três por componente curricular. Essa equipe é chamada de governança central na política de implementação da Base. A governança central linca com as equipes regionais que multiplicam os professores de cada local. Cada Diretoria Regional de Educação do Estado, temos dez, cada diretoria montou uma equipe de formadores. Essas equipes recebem as formações da governança central e são responsáveis por fazer a formação chegar até os professores daquela diretoria. Então a Base está chegando, está sendo implementada através de um esquema de cascata, onde há a governança central, regional e local para elaboração do currículo, formação continuada e acompanhamento. Em junho e julho de 2019, fizemos os seminários de reelaboração dos PPP, à luz da BNCC e do Currículo de Sergipe. Foram 14 seminários em todo o território sergipano. Em setembro fizemos o módulo 1 de formação, com toda a fundamentação teórica da Base e do Currículo. Em dezembro houve o módulo 2 de formação: metodologias ativas e avaliação formativa. E até o final do mês de março agora vamos fazer o módulo 3 , com o plano de curso para os projetos com os temas transversais e integradores previstos na BNCC. (João Manoel) (informação verbal).

As informações passadas por João Manoel demarcam temporalmente a aplicação da logística do ProBNCC de impor às escolas a revisão dos seus projetos pedagógicos antes que a etapa de formação dos professores se realize. A revisão dos PPP das escolas públicas de Sergipe foi realizada em junho e julho de 2019, enquanto o primeiro módulo de formação foi iniciado em dezembro. Os 14 seminários regionais aconteceram localmente, nas Diretoria Regionais da SEED, reduzindo-se a um número de sessões muito aquém da necessidade de produzir modificações necessárias nos PPP para que o trabalho pedagógico das escolas se conformasse ao novo currículo. Nesse sentido, a logística do ProBNCC certamente atingiria melhores resultados se a revisão dos PPP fosse constituída como um dos ciclos de implementação da Base, que ocorreria após a formação dos professores, não como uma etapa diluída entre os ciclos 1 e 2.

Em outro momento, Isabella se volta para a questão lançada por Paulo de que a partir do currículo estadual as escolas deveriam ser mobilizadas para construírem os seus próprios currículos de acordo com as particularidades políticas e pedagógicas que thes são pertinentes, antes da modificação dos seus projetos pedagógicos. Isabella explicou também como o Currículo de Sergipe está atrelado ao sistema de avaliação da Educação Básica do Estado.

Paulo fez algumas provocações relacionadas a porque não é a escola que faz o currículo. Assim ela teria suas especificidades e enfim... Será que o 
Estado não está engessando? Perguntou também como vai ser a avaliação a nivel estadual. Enfim, eu vou tentar dialogar a partir dessa perspectiva. Bem, como a gente explicou, o ponto de partida para fazer o Currículo de Sergipe foi o ProBNCC de que a gente está falando. Os professores das Redes estão ai fazendo a formação e colocando esse Currículo em ação. A gente entende, professor, que o papel da escola nesse contexto é reavaliar o seu próprio Projeto Político Pedagógico, que no caso da Educação Infantil e do Ensino Fundamental já está proposto e já foi encaminhado às Diretorias de Inspeção Escolar, estando para ser encaminhado ao Conselho Estadual de Educação. Então, a escola dá a sua identidade às práticas no seu Projeto Político Pedagógico. Isso é uma coisa importante. Outra coisa importante, é que se a gente tem as avaliações institucionais como é o SAEB por exemplo, que avalia os estudantes do segundo, quinto e nono anos do Fundamental e o terceiro ano do Ensino Médio. A gente vai ter sim uma avaliação estadual que é o SAESE, que foi aprovado pela Assembleia Legislativa no ano passado, em 2019. Agora, instituiu-se na Secretaria estadual de Educação uma Coordenadoria de Avaliação, que vai aplicar o SAESE e tratar os dados da avaliação. Essa é uma outra pasta, há uma outra pessoa que a representa, mas eu só estou respondendo à pergunta de Paulo. Como é que a educação de Sergipe vai ser avaliada? Ela vai ser avaliada já nessa perspectiva, dos currículos que estão sendo implementados e já observando a regionalidade. Vai ser o sistema de avaliação de Sergipe, que é o SAESE e está ligado ao Plano Nacional de Educação. (Isabella) (informação verbal).

A explanação de Isabella reforça as teses de centralização curricular em voga nas políticas educacionais brasileiras após a BNCC, cujas consequências em termos da melhoria de qualidade do trabalho escolar parecem ser, senão desastrosas, bastante emblemáticas. A explanação destaca a criação de estruturas para a gestão do novo currículo dos Estados, como é caso da Coordenadoria de Avaliação da SEED em Sergipe, que se aplica à organização do SAESE. 0 ProBNCC também se incorporou à estrutura da SEED para a gestão do novo currículo. Os PPP são os aportes documentais produzidos a nível da escola para dar sustentação à implementação da BNCC nas redes, mas é conveniente lembrar que dada a logística definida pelo ProBNCC os projetos pedagógicos estão sendo encaminhados às instâncias de homologação e aprovação com poucas modificações em relação às suas versões anteriores. Dessa forma, os PPP, que a princípio são os instrumentos de gestão para o trabalho didático-pedagógico a nível da escola, nem mesmo esta função basilar conseguem cumprir tendo em vista as transformações curriculares que estão sendo implementadas. Definitivamente, parece que de fato há um equívoco nas políticas desenvolvidas para a implementação da BNCC, pois falta o propósito de que as escolas estabeleçam as especificidades de seu currículo antes que ela reveja o PPP.

A respeito da redação da parte diversificada do currículo, João Manoel esclareceu sobre as possibilidades segundo as quais ela pode ser feita. Deve-se ressaltar que a parte diversificada, destinada a dar conta das necessidades educacionais específicas das 
instituições educacionais, na visão adotada pelo ProBNCC termina sendo a mesma para todas as escolas de cada Estado brasileiro.

Para entendimento da parte diversificada proposta na BNCC, ela não é
somente criar habilidades novas, mas pode-se modificar o que já está na
Base. Na redação das habilidades você tem: verbo, o objeto de conhecimento
que é o conteúdo que a gente quer que o aluno aprenda como conceito
e os modificadores. No modificador, você pode aprofundar o conteúdo da
habilidade, ou contextualizar. Uma forma de contextualizar é com os temas
transversais integradores obrigatórios ou com as necessidades cotidianas
que rodeiam a instituição educacional. Então, para os temas que vão surgir
na parte diversificada, você modifica o que está na Base. Além disso, você
tem o entendimento da parte diversificada como componentes curriculares
novos, com habilidades novas. Segundo a Resolução $2 / 2017$ do CNE, você
pode diversificar dessa forma o currículo. (João Manoel) linformação verbal).

João Manoel não abordou nessa sua fala a questão colocada por Paulo sobre - problema que o Currículo de Sergipe apresenta quando pressupõe uma progressão cognitiva para a formação de habilidades na parte diversificada, demandando hierarquias de aprendizagens com as quais a BNCC não trabalha. Deve-se destacar a dificuldade apontada na Seção 2 deste artigo sobre a indiferenciação presente no texto da Base entre objetivos de aprendizagem e desenvolvimento e formação de habilidades. Essa dificuldade de origem torna complexo o trabalho com o conceito de habilidade, principalmente quando se trata de redigir sobre uma que é nova na contemplação da parte diversificada. A esse respeito, a fala de Marcos André foi incisiva com relação à área de Língua Portuguesa, dentro da qual ele atua na SEMED como coordenador de formação continuada.

\begin{abstract}
No caso de Língua Portuguesa, nós temos um monstrengo lá na BNCC de quase 400 habilidades. Então, nós enquanto Currículo de Sergipe não criamos mais habilidade nenhuma. Não estranhem quando vocês pegarem - Currículo de Sergipe e nas outras áreas observarem que além daquela codificação da BNCC, no final dela vai aparecer SE. Isso porque ali foi uma habilidade criada por um grupo de redatores, que em comum acordo, coletivamente, perceberam que estava faltando uma habilidade nova. Gente, criar habilidades não é algo tão simples assim. Existe toda uma discussão internacional, todo um trabalho e percebemos que nós estamos muito atrasados. (Marcos André) (informação verbal).
\end{abstract}

Além dos problemas conceituais e técnicos apontados, as dificuldades na elaboração da parte diversificada, que não são exclusivas do Estado de Sergipe, não poderiam ser compreendidas sem considerar o contexto político que permeou a produção da BNCC, em que os interesses do Terceiro Setor passaram em um certo momento a determinar 
o processo de elaboração de documento. Em sua fala, Silvana interpretou os interesses políticos do setor privado que permearam a produção da BNCC.

Nós estamos diante de uma desinstitucionalização do sistema público de educação. E aí, nós temos que entender a BNCC dentro do conjunto de políticas que acompanharam a sua elaboração. Ela não vem sozinha, mas acompanhada de todo um sistema de facilitação para ação dos agentes que têm interesse na privatização da nossa educação pública. A codificação dos conteúdos é um exemplo, pois auxilia profundamente a elaboração do material didático que no Brasil está nas mãos das grandes editoras e de outras instituições privadas não é de hoje. Coincidentemente, na elaboração da terceira versão, sairam os especialistas das universidades e das escolas públicas, ou eles ficaram meio que ali fazendo o papel de figurantes e entra a Fundação Vanzolini. Esta fundação do setor privado voltada para a educação, tem feito o apostilamento do currículo do Estado de São Paulo, e vejam só gente, isso já tem mais de dez anos. São Paulo, até mesmo pelo poder econômico que o Estado goza, ele não tem figurado como tendo os melhores desempenhos em educação. Então, tem uma Fundação que dá orientação sistemática ao sistema de ensino de São Paulo, que não tem bom resultado e aí a mídia fica quieta. Não se fala quase nada sobre isso. Agora que nossas escolas se saem mal é a escola pública que está fadada ao insucesso. Essa mesma Fundação ganhou 18 milhões para fazer a BNCC, fez em alguns meses. Eu imagino que ela teve que pagar muitos especialistas para fazer a última versão da BNCC, com a presença muito protagonizadora mesmo de outras fundações privadas que atuam no ramo do ensino: Fundação Lemann, Natura, Ayrton Senna, Bradesco, Itaú etc. e tal. (Silvana) (informação verbal).

A fala de Silvana fornece fundamentos analíticos para a compreensão da perspectiva apontada na Seção 1 deste artigo, de que os interesses do Terceiro Setor estão profundamente impregnados do objetivo de valorizar a parte comum do currículo em detrimento das necessidades oriundas das diversidades sociais existentes nas regiões e escolas brasileiras. Pode-se inferir que depois do ProBNCC executar suas tarefas e ser extinto, possivelmente haja um apostilamento das escolas brasileiras, realizado por meio de instituições privadas como forma de dar manutenção ao novo currículo que foi implementado. Isso sem considerar o lucrativo negócio dos cursos de formação continuada, filão para o qual as fundações educacionais estão de olho aberto para abocanhar.

Diversos momentos da fala de Ana Débora na roda de conversa, a seguir articulados na forma de texto narrativo, mostram o que a Rede Municipal de Aracaju está fazendo em termos da produção de material didático para a formação continuada durante a vigência do ProBNCC. 
No ano passado, em 2019, a gente iniciou a construção dos cadernos pedagógicos da rede. Fizemos encontros presenciais, a gente botou a cara e foi discutir currículo com o professor. Foram cinco encontros nos sábados pela manhã, numa rede de $१ २ 0$ professores. Tivemos sábados em que havia 400 professores participando desses encontros. $E$ cada encontro tinha como resultado um texto breve feito por grupos de professores. Esses textos eram as vozes e as falas dos professores, que a gente levou para os cadernos pedagógicos. Esses cadernos já foram finalizados e estão na fase de diagramação. 0 primeiro encontro tratou deste tema: 0 que é o currículo? 0 que quer o currículo da nossa Rede Municipal? 0 segundo texto tratou do tema: Quem são os sujeitos que aprendem? É preciso compreender como são nossos alunos, como eles se desenvolvem, como eles constroem suas subjetividades e como a gente os auxilia como professores. No terceiro texto a gente trabalhou o sujeito professor, a docência, sobre o que é o trabalho de docência, os saberes necessários para ensinar. Então, quem é esse sujeito professor que está na sala de aula? No encontro seguinte, partimos para a metodologia. A BNCC deixa bem claro o viés das metodologias ativas, certo? Então, como ensinar? Depois veio o tema da avaliação. Foi o tema mais polêmico para a gente, porque os professores discutiram como a avaliação pode ser mais que a prova de avaliar para dar nota, a avaliação somativa. Todos os nossos colegas têm a compreensão de avançar, mas com a dificuldade de sair do lugar comum. A última pauta dos cadernos pedagógicos foi a educação inclusiva. Mas não deu tempo, a gente entrou em férias e tinha prazo para fazer a entrega dos cadernos. Então, a gente parou em educação inclusiva, mas vai continuar. A gente produziu os cadernos pedagógicos para não ficar na dependência dos livros didáticos. As empresas privadas já vêm pautando o nosso currículo a longos anos. Tanto que a BNCC foi homologada em dezembro de 2017, mas em agosto já houve a escolha do livro didático com as coleções já adaptadas. Então, é como se eles já tivessem a informação antecipada do que iria acontecer. Como Silvana está apontando, cada vez mais a relação do público com o privado se torna visível na educação do nosso país. (Ana Débora) (informação verbal).

No Brasil, o terreno do livro didático propriamente dito, aquele voltado para a aluno e que o professor usa indiscriminadamente quando sua formação é deficitária, já está dominado pelo setor privado, de uma forma quase sempre realizada por meio de relações pouco legítimas com o setor público. Neste cenário, a fala de Ana Débora é um alento, ao mostrar o enfrentamento da Rede Municipal de Aracaju contra o avanço da privatização da educação pública brasileira no que tange à preparação do material didático para a formação de professores. Ela realiza uma detalhada descrição da natureza e dos conteúdos dos cadernos pedagógicos que foram construídos, demonstrando como eles se adequam à finalidade de subsidiar o currículo em termos da diversidade das escolas da Rede Municipal de Aracaju, particularmente no que diz respeito às características específicas de aprendizagem dos seus alunos. Pudessem esses cadernos ser produzidos continuamente, certamente muito do que corresponde à parte diversificada estaria presente como realidade tangível para os professores dentro da escola. Porém, os recursos do ProBNCC são finitos e a 
singela forma encontrada para produzir material didático subsidiário à formação docente para implementação do Currículo de Sergipe deixará de existir. Com isso, as porteiras então ficarão completamente abertas para o avanço dos interesses privados. É preciso lembrar que Aracaju é a capital do Estado, cuja rede de educação é a mais capacitada em relação aos demais municípios. Estes, não têm como se proteger e certamente seus territórios de formação continuada já foram invadidos pelo Terceiro Setor. Notícias a respeito é que não faltam!

\section{CONSIDERAÇÕES FINAIS}

As falas selecionadas foram fundamentais para o entendimento e a descrição analítica do processo de implementação da BNCC em Sergipe, pois somente a revisão bibliográfica e o levantamento documental seriam insuficientes para que as imprescindíveis nuances exprimidas pelos colaboradores presentes na roda de conversa fossem reveladas. 0 documento estadual redigido é uma mostra típica do atual estágio da produção curricular no Brasil, que sob a influência da BNCC e sua implementação passa por uma fase extremamente auspiciosa, mesmo que diante de fragorosos desacertos. Por outro lado, o esgotamento dos recursos destinados a subsidiar o processo de implementação por meio de agentes do sistema público faz com que haja uma aproximação cada vez maior deste com o setor privado.

\section{REFERÊNCIAS}

BRASIL. LDB: lei de diretrizes e bases da educação nacional. Brasilia, DF: Senado Federal, Coordenação de Edições Técnicas, 2017 .

BRASIL. 0 Todos é suprapartidário e independente. Todos pela educação, 2020. Disponível em: https:// www.todospelaeducacao.org.br/pag/quem-somos/. Acesso em: 11 fev. 2020.

BRASIL. Ministério da Educação. Base Nacional Comum Curricular: Educação é a base. Brasília: MEC, 2017b. Disponivel em: http://basenacionalcomum.mec.gov.br/images/BNCC_El_EF_110518_versaofinal_site.pdf. Acesso em: 5 fev. 2020.

BRASIL. Ministério da Educação. Resolução CNE/CP n 2, de 22 de dezembro de 2017. Institui e orienta a implantação da Base Nacional Comum Curricular, a ser respeitada obrigatoriamente ao longo das etapas e respectivas modalidades no âmbito da Educação Básica. Brasilia, DF: MEC, 2017c. Disponível em: http://portal.mec.gov.br/todas-as-noticias/323-secretarias-112877938/orgaos-vinculados-82187207/53031-resolucoes-cp-2017. Acesso em: 15 jan. 2018. 
BRASIL. Programa de Apoio à Implementação da BNCC - ProBNCC: documento orientador 2019. Brasília, DF: MEC/Secretaria de Educação Básica, 2019. Disponivel em: http://basenacionalcomum.mec.gov.br/ images/implementacao/doc_orientador_probncc_2019.pdf. Acesso em: 29 fev. 2020.

CLANDININ, D. J.; CONNELLY, F. M. Pesquisa narrativa: experiência e história em pesquisa qualitativa. 2. ed. Uberlândia: EDUFU, 2015.

D'ÁVILA, J. L. Política de formação docente executada pelo terceiro setor: considerações sobre a Fundação Lemann. In: CONGRESSO NACIONAL DE EDUCAÇÃ0, 11., 2013, Curitiba. Anais eletrônicos [...] Curitiba: Pontificia Universidade Católica do Paraná, 2013. p. 11558-11569. Disponível em: https://educere.bruc. com.br/CD2013/pdf/10301_5770.pdf. Acesso em: 6 fev. 2020.

FIERA, L. As teias de interesses e influências nas redes de políticas educativas na América Latina e Caribe. Roteiro, Joaçaba, v. 44, n. 3, p. 1-20, set./dez. 2019.

FUNDAÇÃO LEMANN. A aprovação e a homologação da BNCC: Conselho Nacional de Educação e Ministério da Educação aprovam a Base Nacional Comum Curricular. [S. l.: s. n., 2017. Disponivel em: https:// fundacaolemann.org.br/noticias/a-aprovacao-e-a-homologacao-da-bncc?. Acesso em: 6 fev. 2020.

FUNDAÇÃO LEMANN. Trabalhamos por um país mais justo, inclusivo e avançado. [S. L.: s. n.], 2020. Disponível em: https://fundacaolemann.org.br/somos. Acesso em: 6 fev. 2020.

GUIA DE IMPLEMENTAÇÃO BNCC. Guia de Implementação da Base Nacional Comum Curricular. Orientações para o processo de implementação da BNCC. [S. l.: s. n.], 2018. Disponivel em: https://implementacaobncc.com.br. Acesso em: 26 fev. 2020.

LACERDA, M. P. A proposta de um currículo nacional. 1 vídeo $(22 \mathrm{~min}$ ). Publicado pelo Canal Fundação Lemann. [S. l.: s. n., 2012. Disponivel em: https://www.youtube.com/watch?2v=N5vzTo60Nrs. Acesso em: 12 fev. 2020.

LOPES, A. C. Articulações de demandas educativas (im)possibilitadas pelo antagonismo ao "marxismo cultural". Arquivos analíticos de políticas educativas, v. 27, n. 109, p. 1-21, 2019. Disponível em: https:// epaa.asu.edu/ojs/article/view/4881/2303. Acesso em: 15 abr. 2020.

MOVIMENTO PELA BASE. Necessidade e construção de uma Base Nacional Comum. [S. l.: s. n.], 2015. Disponivel em: http://movimentopelabase.org.br/wp-content/uploads/2015/09/Necessidade-e-construcao-Base-Nacional-Comum.pdf. Acesso em: 11 fev. 2020.

MOVIMENTO PELA BASE. Novidades sobre a Base: A BNCC é homologada. [S. L.: s. n.], 2017a. Disponível em: http://movimentopelabase.org.br/acontece/bncc-homologada/. Acesso em: 11 fev. 2020.

MOVIMENTO PELA BASE. Quem somos. [S. l.: s. n., 2017b. Disponivel em: http://movimentopelabase.org. $\mathrm{br} /$ quem-somos/. Acesso em: 11 fev. 2020. 
PIAGET, J. 0 nascimento da inteligência na criança. Rio de Janeiro: Guanabara, 1987.

SERGIPE. Currículo de Sergipe: Educação Infantil e Ensino Fundamental. Regulamentado no Sistema Estadual de Ensino por meio do Parecer n 388/2018/CEE e da Resolução n 04/2018/CEE. Aracaju: Câmara Municipal, 28 dez. 2018a. Disponível em: https://www.seed.se.gov.br/arquivos/CURRICULO. DE.SERGIPE.v.02-Regulamentado.pdf. Acesso em: 14 jan. 2020.

SERGIPE. Secretaria de Estado da Educação/Conselho Estadual de Educação (CEE-SE). Resolução Normativa $n^{\circ} 4$, de 29 de novembro de 2018. Regulamenta a implementação do Currículo do Estado de Sergipe nas redes de ensino e nas instituições educacionais integrantes do Sistema de Ensino, e dá providências correlatas. Diário Oficial, Aracaju, 13 dez. 2018b. Disponivel em: https://www.cee.se.gov. br/arquivos/Resolucao.Normativa.n.4.2018.Curriculo.de.Estado.pdf. Acesso em: 26 fev. 2020.

UNIÃO NACIONAL DOS DIRIGENTES MUNICIPAIS DE EDUCAÇÃO. Conheça o Guia de implementação da Base Nacional Comum Curricular. [S. l.: S. n.], 2018. Disponível em: https://undime.org.br/noticia/05-04-2018-16-34-conheca-o-guia-de-implementacao-da-base-nacional-comum-curricular. Acesso em: 26 fev. 2020.

Endereço para correspondência: Avenida Vereador Olimpio Grande, s/n, 49506-036, Itabaiana, Sergipe, Brasil; paulomarchelli@hotmail.com 
